Predicting secondary organic aerosol phase state and viscosity and its effect on multiphase chemistry in a regional-scale air quality model

Ryan Schmedding et al.

Correspondence to: William Vizuete (vizuete@unc.edu)

The copyright of individual parts of the supplement might differ from the CC BY 4.0 License. 


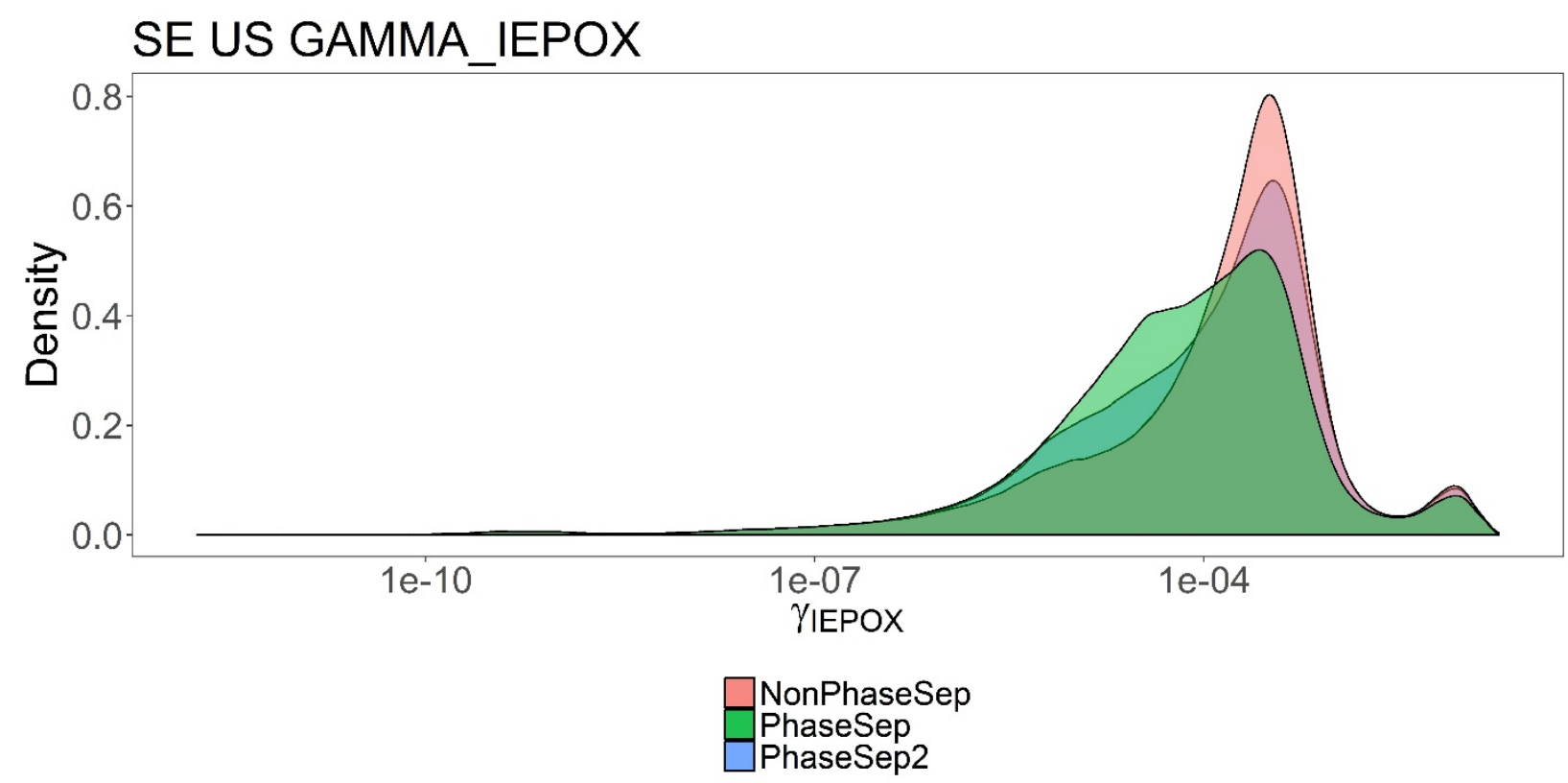

Figure S1 - For Southeastern United States, Probability distribution of $\gamma_{\text {IEPOX }}$ at the surface level for the NonPhaseSep (red), PhaseSep (green) and PhaseSep2 (blue) for SOAS 2013 simulation period. 


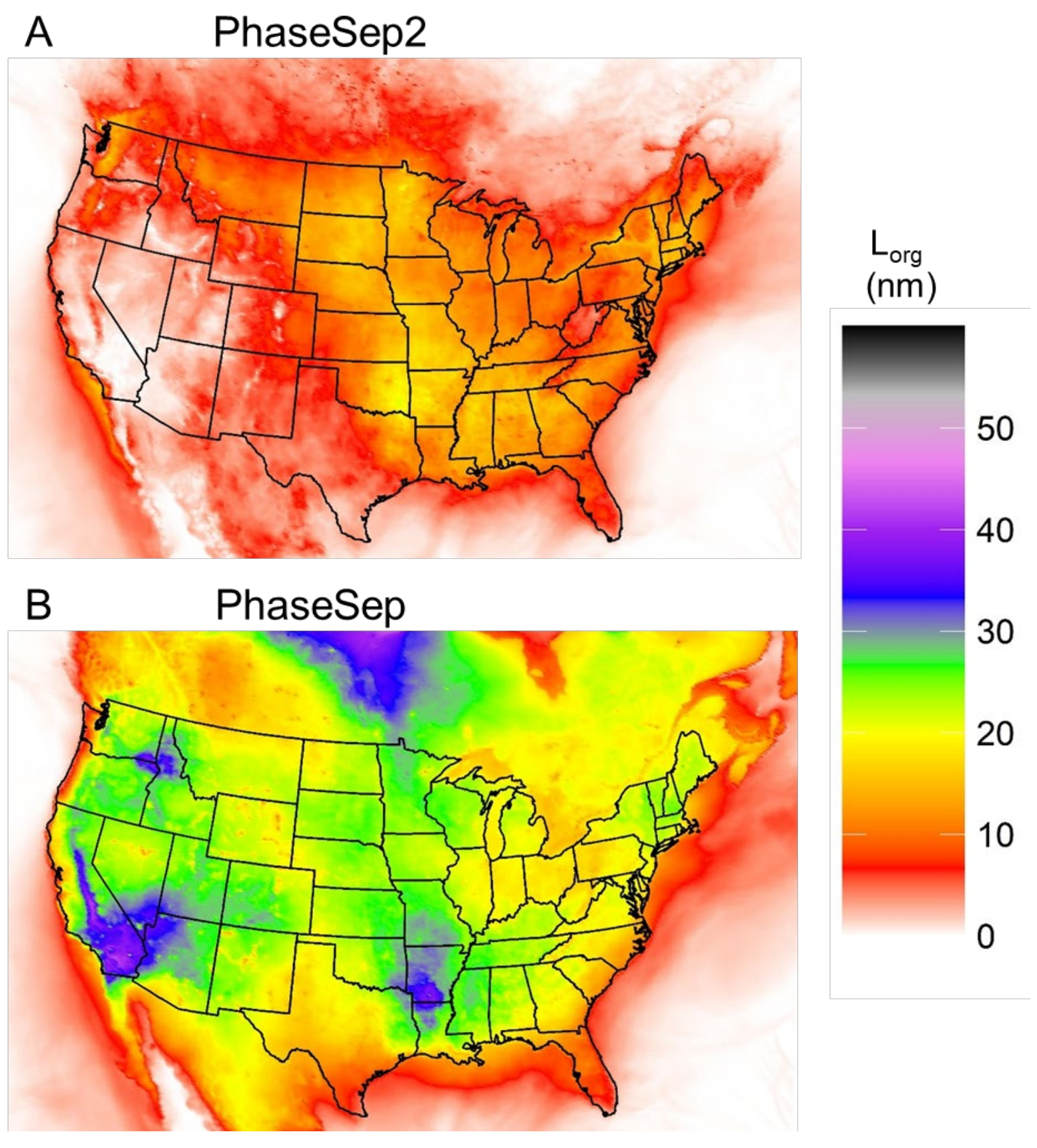

Figure S2 - Average organic coating thickness $\left(l_{\text {org }}\right.$ in $\mathrm{nm}$ ) at the surface level for (A)

PhaseSep2 and (B) PhaseSep cases for SOAS 2013 simulation period. 


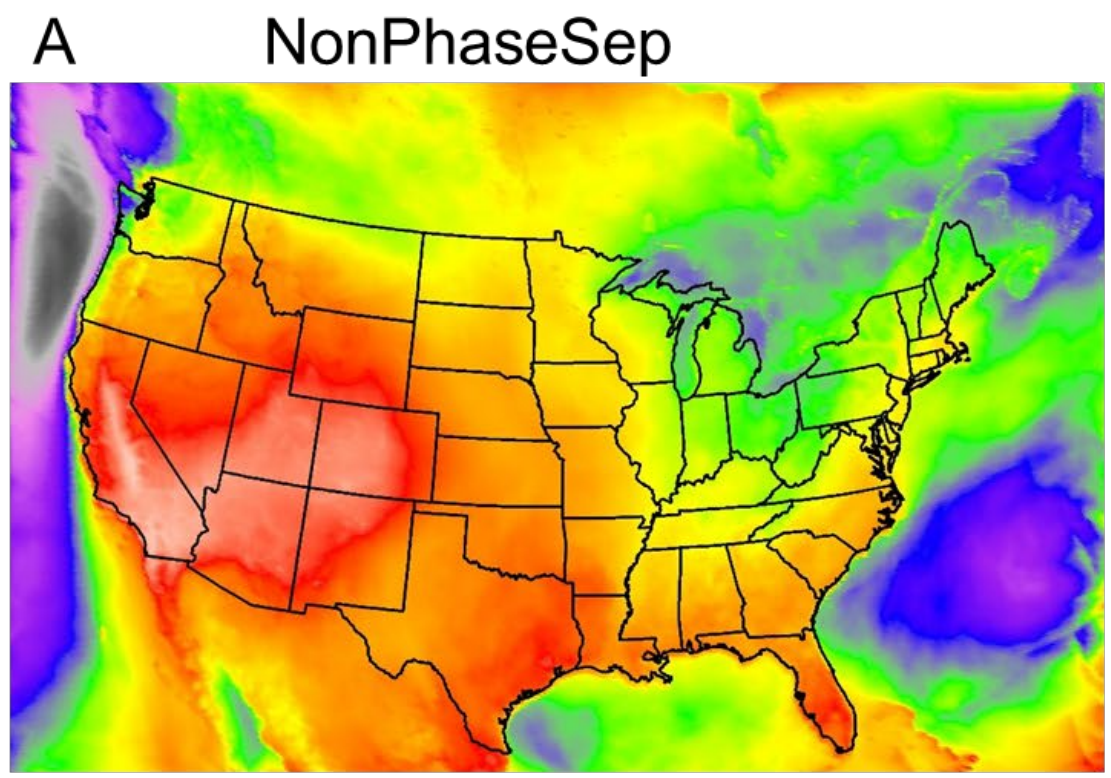

\section{B PhaseSep}

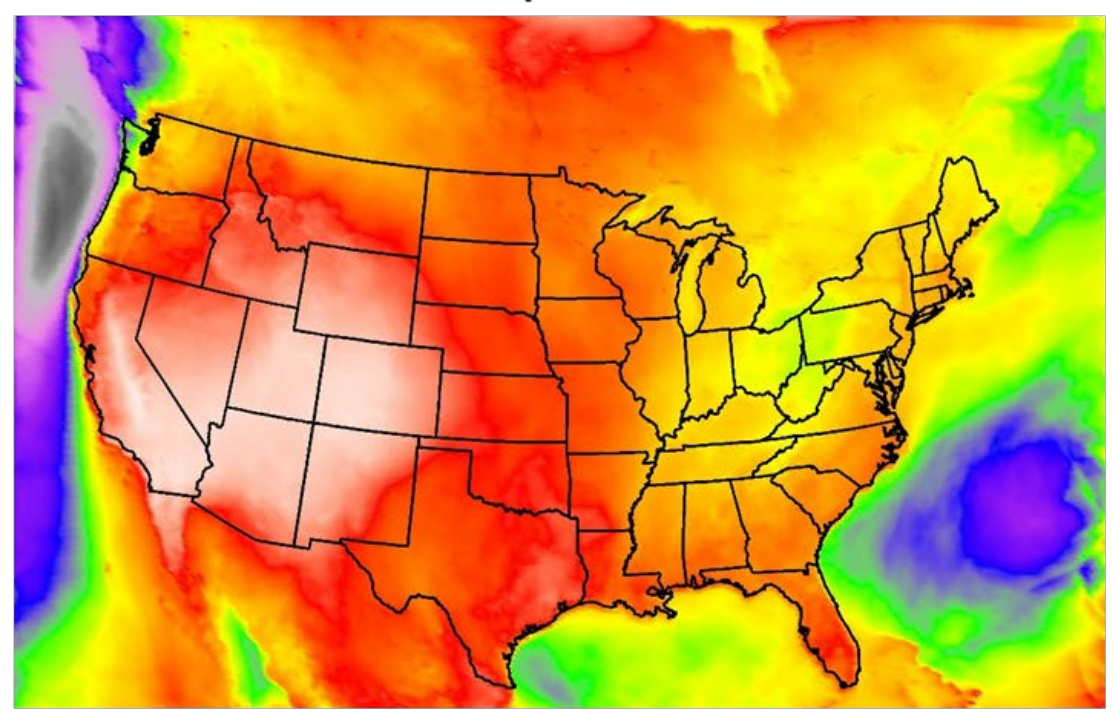

\section{PhaseSep2}

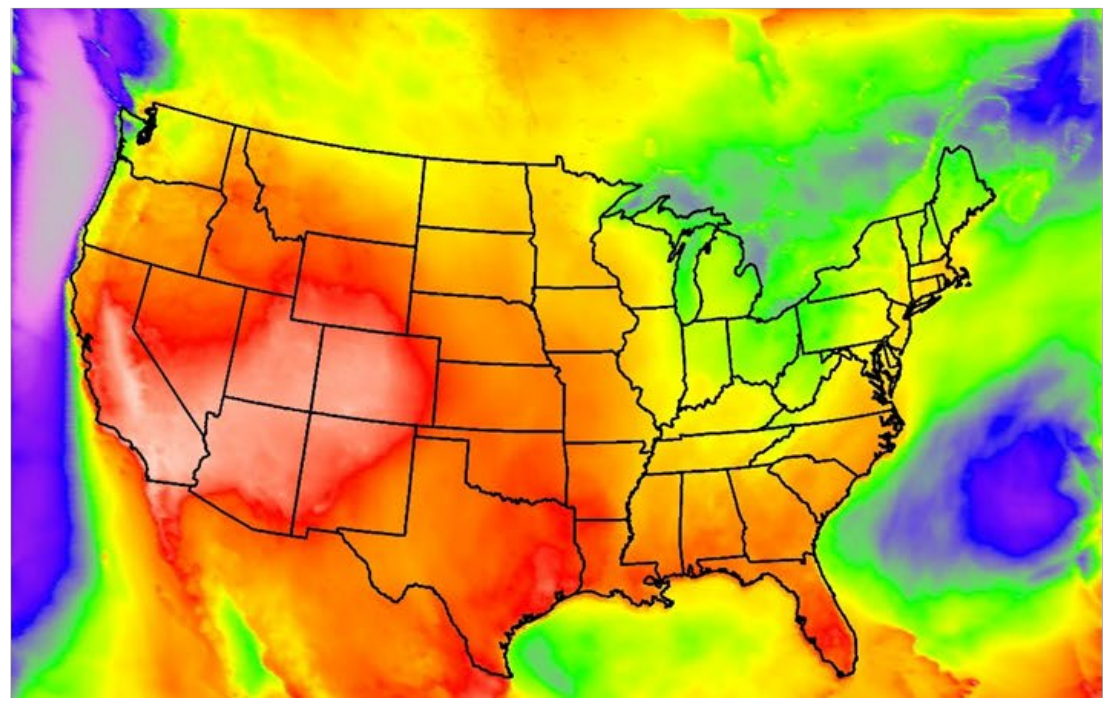

fraction

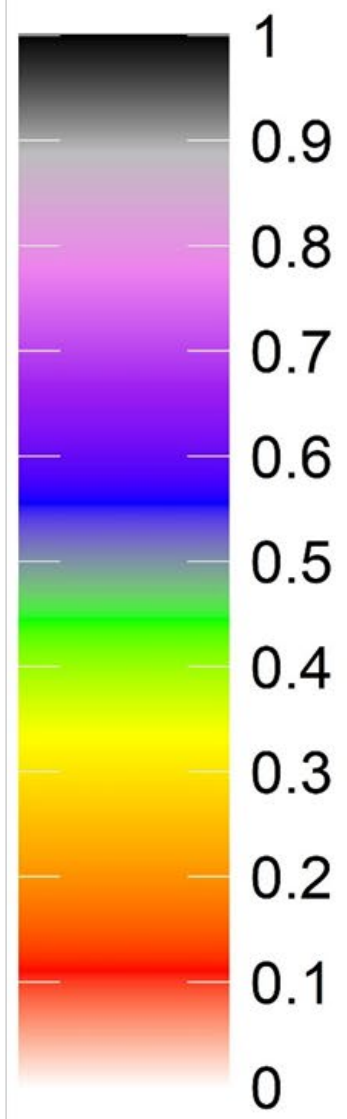


Figure S3 - Average fraction of IEPOX-derived SOA in biogenic SOA mass at the surface level for: (A) NonPhaseSep, (B) PhaseSep and (C) PhaseSep2 case for SOAS 2013 simulation period.

\section{$\%$ change from NonPhaseSep}
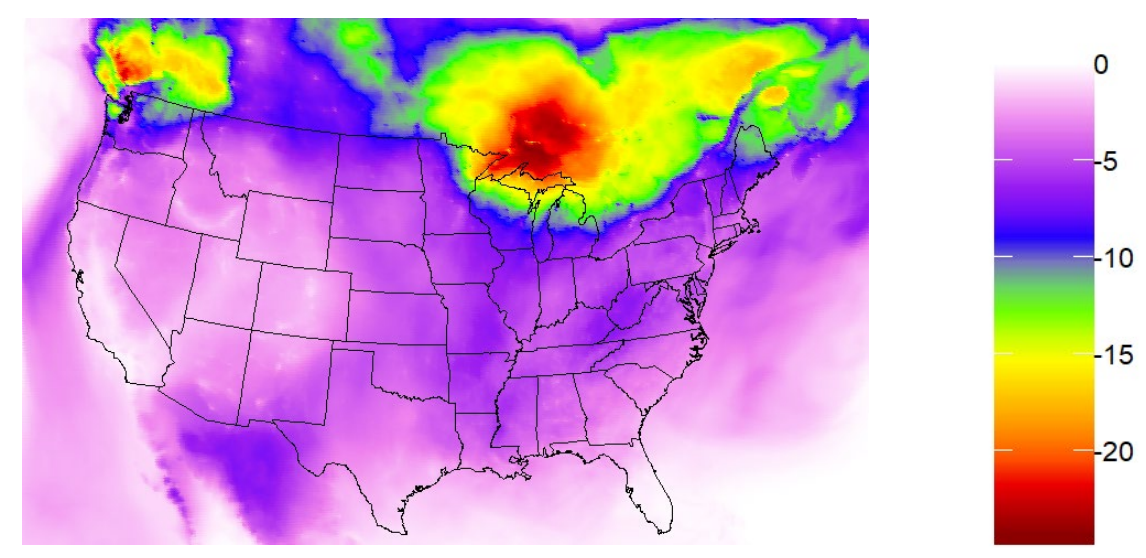

Figure S4 - Spatial map of the mean percent relative change of surface $\mathrm{PM}_{2.5}$ organic carbon (OC) mass in PhaseSep case relative to the NonPhaseSep Simulation.

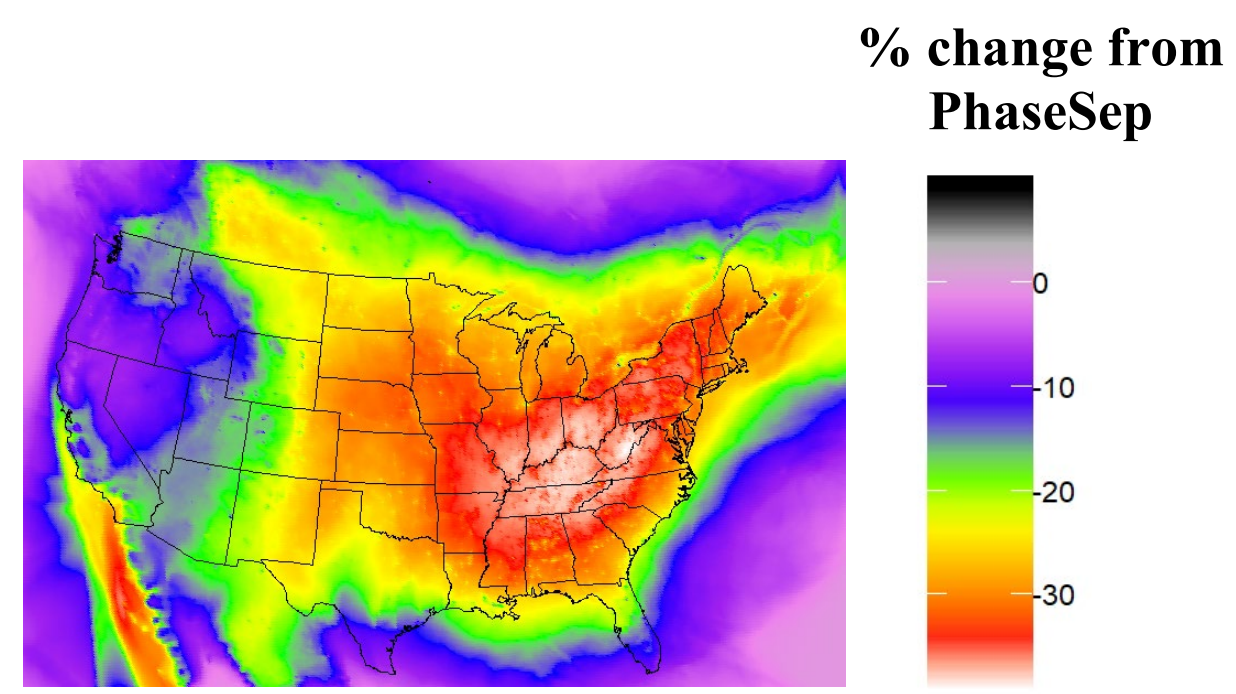

Figure S5 - Spatial map of the mean percent relative change of $\mathrm{PM}_{2.5}$ sulfate mass at surface in Emission Reduction sensitivity case relative to the PhaseSep Simulation. 
Table S1 - Comparison of different simulations on phase separation frequencies (for Continental US) and model performance in isoprene-abundant southeastern United States (rural Centreville, $\mathrm{AL}$ and urban Atlanta sites).

\begin{tabular}{|c|c|c|c|c|c|}
\hline \multicolumn{2}{|c|}{ Parameter (units) } & PhaseSep & PhaseSep2 & $\begin{array}{l}\text { Emissions } \\
\text { Reductions }\end{array}$ & HighHorg \\
\hline \multirow{2}{*}{$\begin{array}{l}\text { For } \\
\text { Continental } \\
\text { US }\end{array}$} & $\begin{array}{l}\text { LLPS } \\
\text { Frequency (\%) }\end{array}$ & 13.7 & 13.7 & 13.5 & 12.5 \\
\hline & \begin{tabular}{|l|} 
SSPS \\
Frequency (\%)
\end{tabular} & 54.8 & 29 & 57 & 55.8 \\
\hline $\begin{array}{l}\text { NMB }(\%, \\
\text { compared to }\end{array}$ & $\begin{array}{l}\text { Rural } \\
\text { Centreville, } \\
\text { AL forest site }\end{array}$ & -36 & -33 & -44 & -32 \\
\hline $\begin{array}{l}\text { SEARCH } \\
\text { PM}_{2.5} \text { OC) }\end{array}$ & $\begin{array}{l}\text { Urban } \\
\text { Jefferson } \\
\text { Street, Atlanta } \\
\text { site }\end{array}$ & -21 & -18 & -29 & -18 \\
\hline
\end{tabular}

